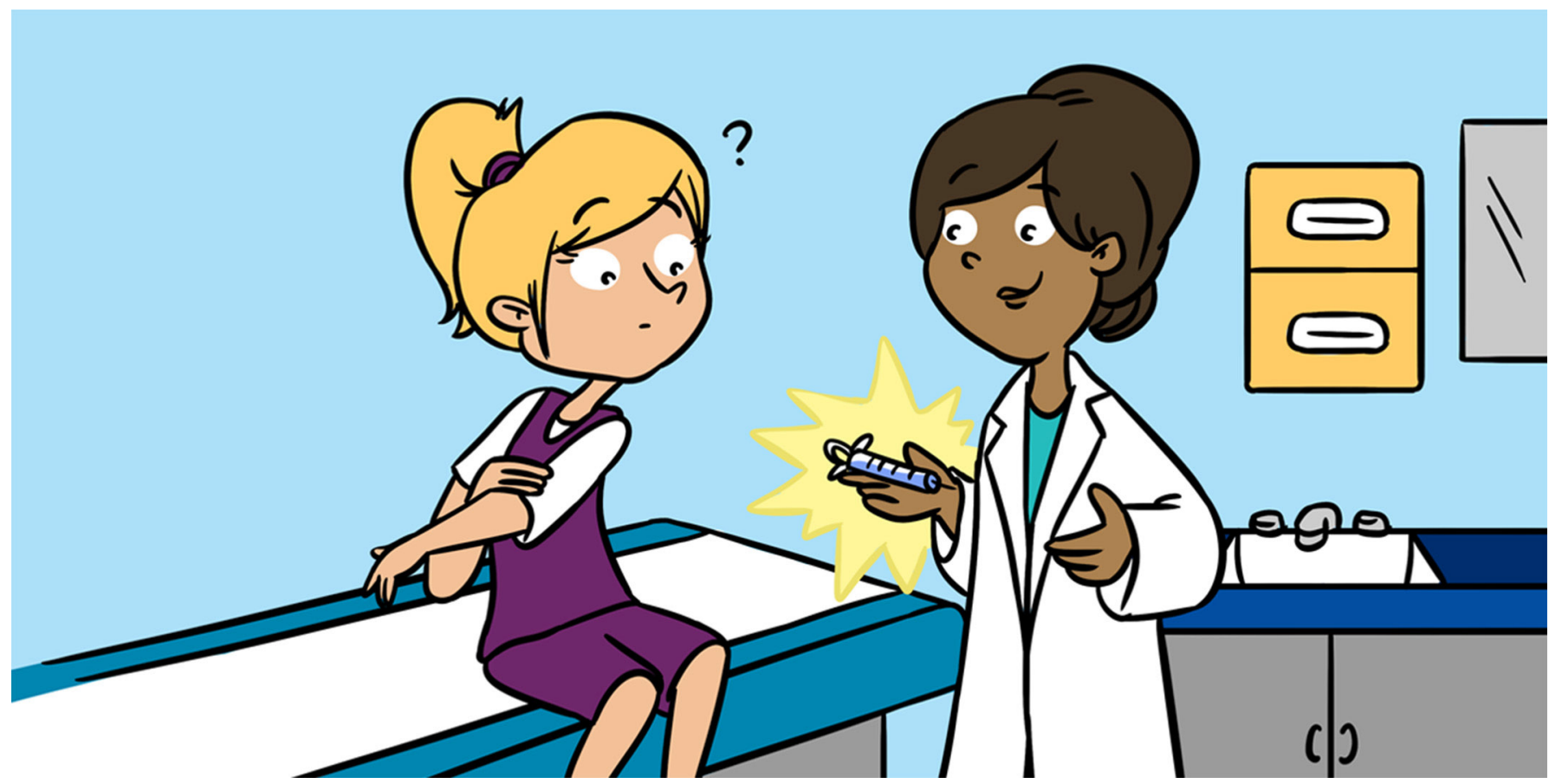

\title{
VACCINES, SHOTS THAT PROTECT YOU
}

\section{Marie Neunez ${ }^{1}$, Michel Goldman ${ }^{1 *}$, Sylvie Goldman² and Paul-Henri Lambert ${ }^{3}$}

1 Institute for Interdisciplinary Innovation in Healthcare, Université libre de Bruxelles, Brussels, Belgium

2 Department of Neurology, Columbia University Medical Irving Center, New York, NY, United States

3 Center of Vaccinology, University of Geneva, Geneva, Switzerland

\section{YOUNG REVIEWERS:}

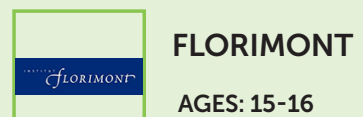

\section{VACCINES}

Substances that protect from diseases caused by microbes.

\section{MICROBES}

Microorganisms that cause infections and diseases such as measles.
Tomorrow, your mother will take you to the doctor to receive your vaccines. Why do you need these shots since you are healthy and have already received some shots when you were just a baby? In this article, you will discover the reasons why booster vaccines are crucial, to protect you, your brothers and sisters but also your classmates and your friends.

\section{VACCINES, ONE OF A KIND DRUGS}

While medicines are usually given to a person who is sick, vaccines are injected to healthy children or adults to keep them from getting diseases that are transmitted by tiny living organisms named microbes. Vaccination is the best way to date to prevent diseases that are called infectious diseases. 
MEASLES

Disease affecting unvaccinated children.

\section{VIRUS}

Small microbe.

\section{MEASLES, A FORGOTTEN INFECTIOUS DISEASE}

When your grandparents were your age, many children suffered from measles, a disease caused by a virus. Most often, they would heal from it, but sometimes, the disease caused serious complications, involving the lungs or the brain, that could be deadly. Thanks to vaccination, measles nearly disappeared completely. This is also the case for several other childhood illnesses, such as poliomyelitis that caused paralysis of the legs. To date, we count more than 10 infectious diseases that are prevented thanks to vaccines. Unfortunately, not all children have the chance to be vaccinated: either because they live in areas of the world where vaccines are not available or difficult to access, or because their parents are against vaccination.

\section{SOME MICROBES CAUSE CANCER}

In certain individuals, long-standing infections can cause cancer. For example, women infected with the human papilloma virus may develop cancer of a part of the uterus, an essential organ for human reproduction. Vaccination is the most efficient way to prevent this cancer from occurring.

\section{MICROBES JUMP FROM ONE PERSON TO THE NEXT}

Microbes can be transmitted from person to person, through different routes. In the case of measles, an infected individual can potentially contaminate up to 20 other persons by spreading the virus in the air. This is what "contagious" means when we talk about an infectious disease. The more contagious is the disease, the more important the vaccination will be.

\section{VACCINATED CHILDREN: A WORLDWIDE CHAIN OF SOLIDARITY AGAINST INFECTIOUS DISEASES}

When you are vaccinated, not only are you protected against the microbe, but you also decrease the risk of transmitting that disease to your friends and family. This is called herd protection (Figure 1). If the majority of the population is vaccinated, microbes will not succeed in propagating. It is believed that when 9 individuals out of 10 are vaccinated, the entire population is protected so that the disease becomes "invisible." However, the disease can resurface at any point if the proportion of vaccinated individuals decreases. Sadly, this is what is happening today with measles and other infectious diseases: within 
Figure 1

Herd protection.

\section{LYMPHOCYTES}

White blood cells that produce antibodies and kill microbes.

\section{ANTIGENS}

Parts of the microbes that are recognized by antibodies.

\section{ANTIBODIES}

Weapons that we produce to attack microbes.

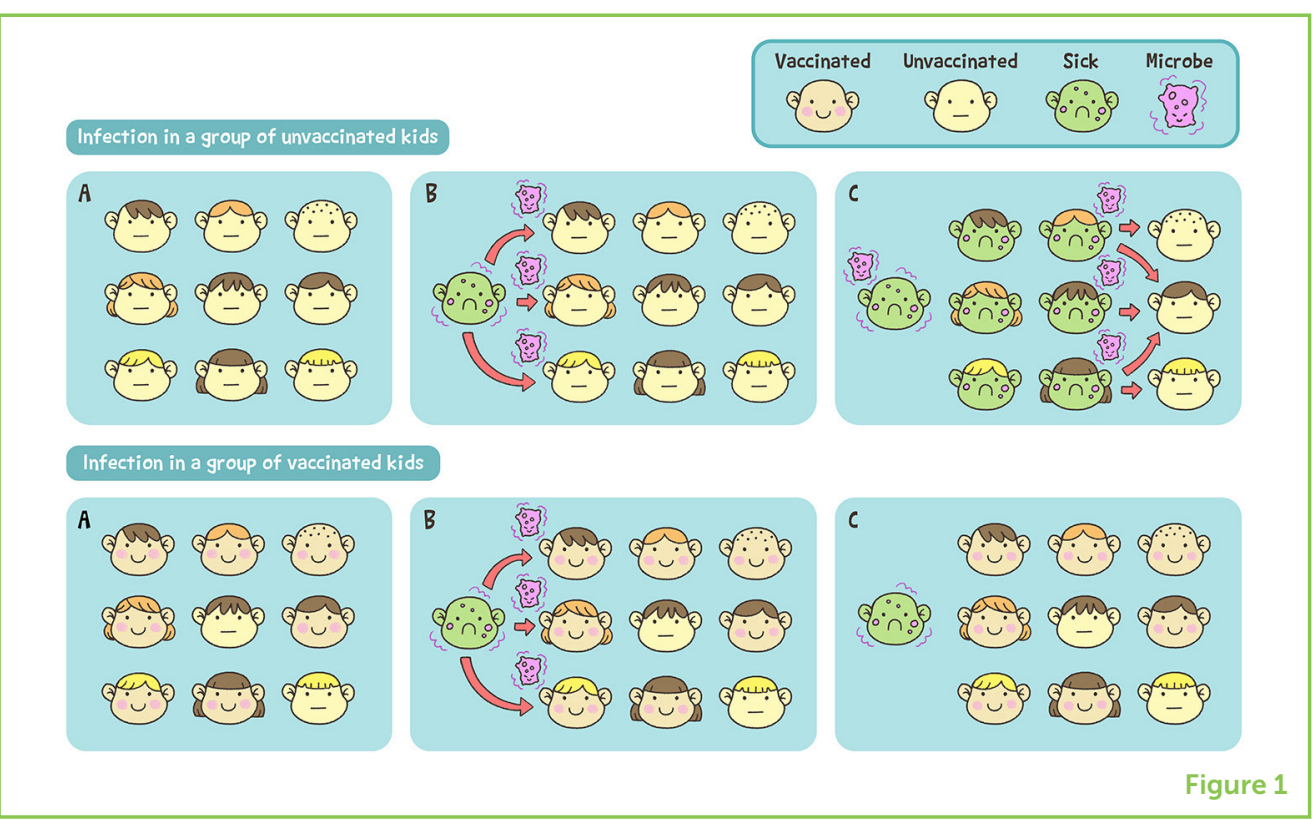

the first 6 months of the year 2018, more than 40,000 Europeans contracted measles while some thought that it had disappeared for good.

Hence, vaccination is critical, have you ever discussed it with your parents? Indeed, vaccination does not stop after childhood. It remains crucial to follow-up and have booster vaccines throughout your life to maintain the benefits of vaccines. This will be explained in the following pages.

\section{THE ROLE OF THE IMMUNE SYSTEM IN INFECTIOUS DISEASES}

To discover what is a vaccine, you first need to understand how our natural defenses work, that is how our immune system acts against dangerous microbes. Within a short time after penetrating our bodies, microbes usually multiply and infect our cells, preventing them from functioning properly. In most cases, we succeed in fighting that enemy thanks to the army of cells that compose our immune system. In some cases, the immune system does not succeed in sufficiently and rapidly getting rid of those aggressive microbes, resulting in the onset of a disease.

When a microbe enters into our bodies, several types or cells come into action. Cells named lymphocytes recognize small pieces of the microbes, the so-called antigens. Each lymphocyte recognizes a specific antigen and then attacks microbes that present this antigen at their surface. Certain lymphocytes act by releasing biological weapons known as antibodies. These weapons that resemble arrows target antigens at the 


\section{Figure 2}

Antibodies produced by lymphocytes bind antigens and kill microbes.

\section{Figure 3}

How vaccines work. surface of microbes and eventually kill them (Figure 2). After the fight, several lymphocytes remember and record the microbe. This memory enables them to rapidly release large amounts of antibodies in case of a future attack. If the latter occurs, those microbes will be destroyed even before you realize that you have been infected.
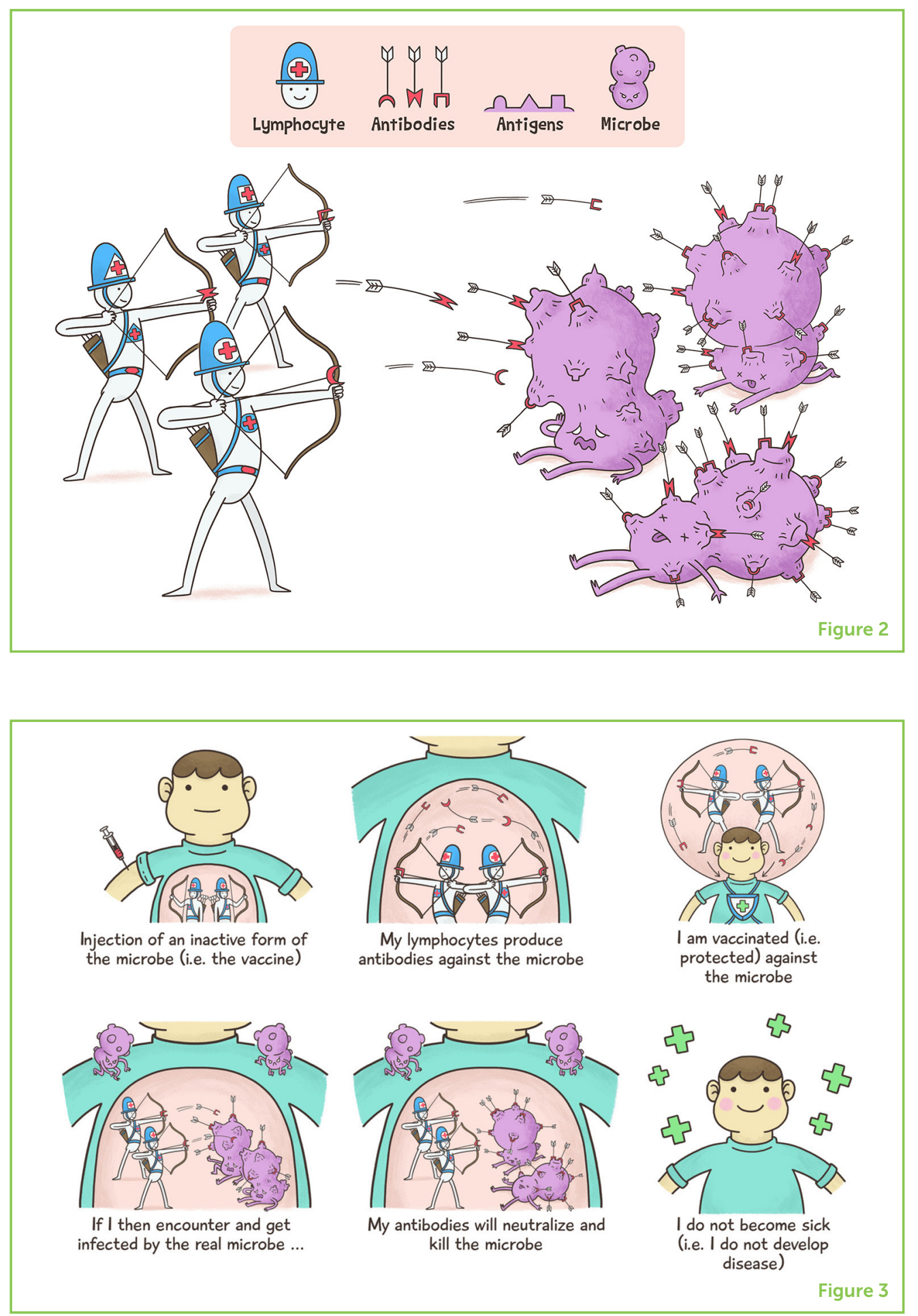


\section{WHAT ARE VACCINES AND HOW DO THEY WORK?}

Vaccines stimulate your immune system without requiring your body to be sick [1]. They contain harmless antigens that provide you with double protection: first, vaccines trigger the production of antibodies that last very long in your body; second, they enable memory of the immune system. This is why when your body encounters the microbe, you immediately kill it (Figure 3).

\section{WHY SO MANY SHOTS?}

As each microbe is different from the other, multiple vaccines have to be used. Do not worry, it is now common to give multiple vaccines in a single shot.

You probably ask yourself: why do I have to receive several times the same vaccine in the course of my life? The answer is simple. As you know, our memory has its limitations and we have the tendency to forget things. This is also true for our immune system. It is therefore necessary to boost its memory by repeating vaccination. Boosters are indeed crucial to maintain effective protection against infectious diseases.

\section{WHO CAN BE VACCINATED?}

Most of the children around the world can be vaccinated. Only a few of them should not, because they suffer from a disease that affects their immune system: they are said to be immunodeficient. Thanks to herd protection, when healthy children are vaccinated, they provide protection for those sick children as well.

Nowadays, vaccines are also given to pregnant women to protect their babies. The vaccinated mother transfers her antibodies to her child during pregnancy and then through breast-feeding. This is important to protect newborns before they can be efficiently vaccinated themselves. An example is whooping cough than can lead to severe respiratory infection during the first weeks of life.

\section{WHAT ARE THE RISKS OF VACCINATION?}

You should know that vaccines can sometimes lead to mild discomfort, but the pinch of a shot is never as bad as the illness caused by a harmful microbe. 
Vaccines that you received have been analyzed in-depth to make sure they are both efficient and safe.

\section{WHY SOME INDIVIDUALS DOUBT ABOUT VACCINATION?}

Unfortunately, the information available to the public on benefits and risks of vaccines is often incomplete or even inaccurate, especially on the internet [2]. Some people believe that infectious diseases are not threatening children anymore and therefore deny the need for vaccination. They forget that if vaccines are not used, diseases will rapidly reappear.

Now that you understand what vaccines are, consider talking about this with your parents.

\section{REFERENCES}

1. Bloom, B. R., and Lambert, P.-H. (Eds.). 2016. The Vaccine Book, 2nd Edn. (San Diego, CA: Academic Press).

2. Arif, N., Al-Jefri, M., Bizzi, I. H., Perano, G. B., Goldman, M., Haq, I., et al. 2018. Fake news or weak science? Visibility and characterization of antivaccine webpages returned by google in different languages and countries. Front. Immunol. 9:1215. doi: 10.3389/fimmu.2018.01215

SUBMITTED: 30 January 2019; ACCEPTED: 07 February 2019;

PUBLISHED ONLINE: 28 February 2019.

EDITED BY: Fulvio D'Acquisto, Department of Life Sciences, University of Roehampton, United Kingdom

CITATION: Neunez M, Goldman M, Goldman S and Lambert P-H (2019) Vaccines, Shots That Protect You. Front. Young Minds 7:31. doi: 10.3389/frym.2019.00031

CONFLICT OF INTEREST STATEMENT: The authors declare that the research was conducted in the absence of any commercial or financial relationships that could be construed as a potential conflict of interest.

COPYRIGHT @ 2019 Neunez, Goldman, Goldman and Lambert. This is an openaccess article distributed under the terms of the Creative Commons Attribution License (CC BY). The use, distribution or reproduction in other forums is permitted, provided the original author(s) and the copyright owner(s) are credited and that the original publication in this journal is cited, in accordance with accepted academic practice. No use, distribution or reproduction is permitted which does not comply with these terms. 

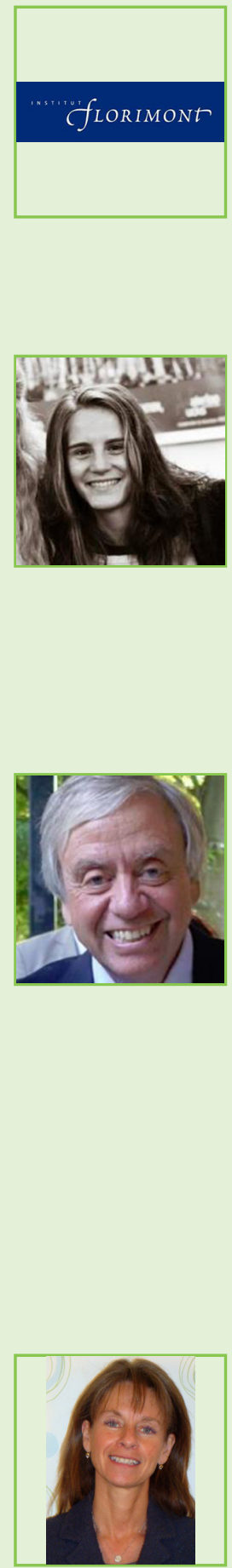

\section{YOUNG REVIEWERS}

\section{FLORIMONT, AGES: 15-16}

In our group, there is Zachary, Paul, George, Sarah, Gabriel, Zeynep, and Klara. We are part of the class 2B2 at Florimont. We worked on the vaccines paper and we found this paper very interesting. We learnt a lot from this article!

\section{AUTHORS}

\section{MARIE NEUNEZ}

I am a part-time research fellow at the I3h Institute and Student in Medicine at the Universite Libre de Bruxelles (ULB). I was a Clinical Research Coordinator for 2 years in the Departments of Nuclear Medicine \& Radiotherapy at the Institut Jules Bordet (IJB). I also performed a 5-months internship at BASF SE (Mannheim, Germany) in the Human Health \& Nutrition department. I hold a MSc degree in Bioengineering with a specialization in Science, Technology and Quality of Food (UCL, Belgium), a Postgraduate degree in Management (ICHEC Business Management School, Belgium) and a certificate in Clinical Studies (Cefochim, Belgium).

\section{MICHEL GOLDMAN}

I graduated as a Medical Doctor (1978) from the Université Libre de Bruxelles (ULB), Belgium, and received my Ph.D. in medical sciences (1981) from the Université de Genève, Switzerland. From 1990 to 2008, I was the chairman of the Department of Immunology at Erasme Hospital in Brussels, and from 2004 to 2009 I served as the first Director of the Institute for Medical Immunology of ULB. From 2009 to 2014, I served as the first Executive Director of the Innovative Medicines Initiative (IMI) a joint undertaking between the European Commission and the European Federation of Pharmaceutical Industries and Associations. Managing a budget of $€ 2$ billion, I was responsible for the launch of 59 public-private consortia in areas of major importance for public health. Currently I am a Full Professor at ULB where I was the Founding Director of the Institute for Interdisciplinary Innovation in Healthcare (I3h). *mgoldmanaulb.ac.be

\section{SYLVIE GOLDMAN}

I graduated in 1984 from the Department of Psychology \& Pedagogical Sciences, Université Libre de Bruxelles (ULB), Belgium. I obtained my Ph.D. in Developmental Psychology from the City University of New York, Graduate Center in 2002. From 2002 to 2009, I held a position of developmental psychologist at the McCarton Center for Developmental Pediatrics. I obtained my post-doctoral training in neuropsychology under the mentorship of Dr. Isabelle Rapin at Albert Einstein College of Medicine, Bronx NY, USA where I became the Co-director of the NIH-Human Clinical Phenotype Core of the R. F. Kennedy Intellectual and Developmental Disabilities Research Center. I am currently an Assistant Professor in the Division of Child Neurology, department of Neurology at Columbia University Irving Medical Center. I am a teaching faculty for the Parent-Infant Psychotherapy Program in Child Psychiatry at Columbia University Irving Medical Center. My current clinical activities and research address the disparities and delays in the diagnosis of autism in girls and minorities. 


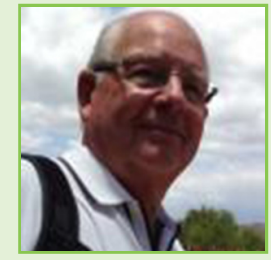

I am a member of the Columbia University Research Consortium on Autism Spectrum and Related Neurodevelopmental Disorders and the Columbia Population Research Center (CPRC). I am the recipient of multidisciplinary seed grants from the Irving Institute, the Department of Neurology, the Columbia Center of Science and the Presidential Scholars in Society and Neuroscience.

\section{PAUL-HENRI LAMBERT}

I am now associated with the Centre of Vaccinology in the Department of Pathology and Immunology at University of Geneva. I am particularly interested in vaccination strategies and evaluation of adverse effects. I am directing the International Advanced Course of Vaccinology (ADVAC) organized under the auspices of the Fondation Mrieux and University of Geneva. I am a member of the Governing Board of the Tuberculosis Vaccine Initiative (TBVI) and chairman of the Human Vaccine Committee of the International Association for Biologicals (IABS). My native is Belgium where I was boarded in Internal Medicine (University of Liege). I joined Frank Dixon at Scripps Institute, La Jolla, California, for my training then moved to University of Geneva Medical School where I became Professor in the Departments of Medicine and of Pathology. My research activities lead me to decipher immunological mechanisms involved in autoimmune and immune complex-mediated diseases, in the pathogenesis of malaria and in new strategies to optimize vaccine immunogenicity. In 1987, I was appointed as Chief Microbiology and Immunology at the World Health Organization and in 1994, Chief, Vaccine Research and Development, WHO Global Programme for Vaccines and Immunization. I was then deeply involved in co-ordination of research aiming at the development of vaccines against diseases of major importance in developing countries. I am an author or co-author of 455 publications, member of several international scientific boards, foreign member of the Royal Academy of Medicine in Belgium and Fellow of the American Association for the Advancement of Science. 